\title{
Análise da contribuição do Programa Bolsa Família para o enfrentamento da pobreza e a autonomia dos sujeitos beneficiários
}

\author{
Maurício Gregianin Testa \\ Pontifícia Universidade Católica do Rio Grande do Sul (PUC-RS) \\ Paula Fronza \\ Instituto Nacional do Seguro Social (INSS) \\ Maira Petrini \\ Pontifícia Universidade Católica do Rio Grande do Sul (PUC-RS) \\ Jane Cruz Prates \\ Pontifícia Universidade Católica do Rio Grande do Sul (PUC-RS)
}

\begin{abstract}
Esta pesquisa reflete sobre a contribuição do Programa Bolsa Família (PBF) para o enfrentamento da pobreza e uma maior autonomia dos sujeitos beneficiários. Foram coletados dados quantitativos com 103 famílias beneficiárias, complementados com entrevistas qualitativas com profissionais e famílias. Entre as formas de privação (educação, saúde, trabalho e renda etc.), a educação mostrou-se o aspecto de privação que obteve os melhores resultados na percepção das famílias na busca da autonomia. A participação em atividades de apoio social tem efeito direto na percepção de melhoria da situação da família; entretanto, a participação das famílias mostrou-se incipiente. Essas atividades contribuem para o desenvolvimento da autonomia e podem ser compreendidas como o principal mecanismo do programa para as pessoas encontrarem as "portas de saída".

Palavras-chave: administração pública; política pública; transferência de renda; pobreza; autonomia.

Análisis de la contribución del Programa Bolsa Familia para el afrontamiento de la pobreza y la autonomía de los sujetos beneficiarios

Esta investigación refleja acerca de la contribución del Programa Bolsa Familia para el afrontamiento de la pobreza y una mayor autonomía de los sujetos beneficiarios. Fueron recogidos datos cuantitativos con 103 familias beneficiarias, complementados con entrevistas cualitativas con profesionales y familias. Entre las formas de privación (educación, salud, trabajo e ingresos etc.), la educación se mostró el aspecto de privación que obtuvo los mejores resultados en la percepción de las familias en la
\end{abstract}

Artigo recebido em 23 nov. 2012 e aceito em 17 jul. 2013.

Rev. Adm. Pública - Rio de Janeiro 47(6):1519-541, nov./dez. 2013 
búsqueda de la autonomía. La participación en actividades de apoyo social tiene un efecto directo en la percepción de mejora de la situación de la familia; sin embargo, la participación de las familias se mostró incipiente. Esas actividades contribuyen al desarrollo de la autonomía y pueden ser comprendidas como el principal mecanismo del programa para las personas encontraren las "puertas de salida".

Palabras clave: administración pública; política pública; transferencia de ingresos; pobreza; autonomía.

Analysis of the contribution of Bolsa Família Program to the confrontation of poverty and the autonomy of beneficiary subjects

This research reflects on the contribution of Bolsa Família Program to the confrontation of poverty and an increased autonomy of beneficiary subjects. Quantitative data were collected with 103 beneficiary families, supplemented with qualitative interviews with professionals and families. Among the deprivation forms (education, health, work and income, etc.), education has proved to be the deprivation aspect which obtained the best results in the perception of families in search for autonomy. Participation in social support activities has a direct effect on the perception of family improved situation; however, the participation of families showed to be incipient. These activities contribute to develop autonomy and they may be understood as the main program mechanism for people to find the "exit doors".

KeYWorDs: public administration; public policy; transfer income; poverty; autonomy.

\section{Introdução}

No contexto atual de políticas públicas da sociedade brasileira identifica-se a existência de diversos programas assistenciais que procuram minimizar as diferenças sociais e buscam contribuir para o desenvolvimento de uma sociedade mais igualitária. É o caso do Programa Bolsa Família, que atende a mais de 13 milhões de famílias em todo o Brasil. O programa foi criado pelo governo federal para dar apoio às famílias pobres na garantia do direito à alimentação, saúde e educação. Consiste na transferência de renda mensal do governo federal às famílias cadastradas que se encontram dentro dos critérios de inclusão (Brasil, 2012).

A análise de índices de desenvolvimento social apresenta indícios de que o Bolsa Família vem contribuindo para a melhoria da situação de muitas famílias (FGV, 2012). Essas melhorias seriam decorrentes do aumento da renda, mas também das condicionalidades para permanência no programa, relacionadas com a educação e saúde. Como parte dos objetivos propostos pelo programa, também está a independização da família, ou seja, espera-se que os beneficiários deixem de necessitar do mesmo ao apresentarem melhorias nas condições de vida e desenvolverem meios próprios de sustento. Essa é uma meta de longo prazo que requer políticas, programas e projetos que possibilitem às famílias chegarem às "portas de saída", como são chamadas as formas de desligamento do programa para aqueles que alcançam tais objetivos.

Neste contexto, questiona-se se os avanços possibilitados pelo PBF estão contribuindo para uma maior autonomia das famílias beneficiadas. Por autonomia, entende-se a capacidade do indivíduo de superar formas de privação da liberdade que o impedem de viver de acor- 
do com seus desejos e valores. Esse conceito foi construído, principalmente, a partir da visão de Sen (2000, 2002), que define liberdade e pobreza como privação das capacidades. Para serem autônomas, as famílias devem ser capazes de superar as privações impostas pela renda, através do trabalho, mas também ser capazes de superar as privações derivadas da baixa educação, dos problemas de saúde, da alimentação pobre, da violência nas relações sociais, entre outros aspectos. Todos esses elementos têm potencial para impedir que indivíduos possam superar uma condição de pobreza e viver de acordo com seus valores e desejos, constituindo, assim, formas de privação da liberdade.

Parte da mídia e da sociedade tem apresentado críticas ao programa acusando-o de assistencialista, destacando que forma dependentes e não cidadãos autônomos. Ressalta ainda que o recebimento do Bolsa Família deveria ser uma situação temporária, que facilitasse a família no processo de reorganização e encontro de uma forma de sustento próprio, possibilitando a novos cidadãos, que necessitam de auxílio, o acesso a este recurso que é escasso e não atinge a toda a população necessitada.

Dessa forma, esta pesquisa tem como objetivo central refletir sobre a contribuição do Programa Bolsa Família para o enfrentamento à pobreza e para uma maior autonomia dos sujeitos beneficiários. A investigação foi conduzida junto a Centros de Referências da Assistência Social (Cras) da cidade de Porto Alegre, nos quais grande parte dos usuários dos serviços oferecidos é de beneficiados pelo Bolsa Família.

\section{O Programa Bolsa Família}

A transferência de renda surge no século XVIII na Inglaterra e vem ressurgindo ao longo dos anos com novas roupagens, na tentativa de garantir a sobrevivência daqueles que se encontram em situação de pobreza. No Brasil, os Programas de Transferência de Renda iniciam sua trajetória em 1991 com a proposta do Programa de Garantia de Renda Mínima (PRGM), o qual se transformou na Renda Básica de Cidadania. O Programa Bolsa Família pode ser considerado a expressão atual do processo de desenvolvimento histórico dos Programas de Transferência de Renda no Brasil (Silva, Yazbek e Giovanni, 2006:34).

Procurando sistematizar o desenvolvimento histórico, Silva (2007) estabelece cinco grandes momentos na trajetória dos Programas de Transferência de Renda no Brasil, considerando o ano de 1991 como o primeiro momento desse processo.

Ainda em 1991, o debate incorpora a ideia de articulação da garantia de uma renda mínima familiar com a educação, associando uma política compensatória (transferência monetária) com uma política estruturante (educação), iniciando seu segundo momento.

O ano de 1995 marcou o terceiro momento desse processo, com o início da implementação de programas nas experiências municipais em Campinas, em Ribeirão Preto e em Santos (São Paulo) e no Distrito Federal. Em 1996 são iniciadas as primeiras experiências de iniciativa do governo federal, com a criação do Programa de Erradicação do Trabalho Infantil (Peti) e do Benefício de Prestação Continuada (BPC), instituído pela Lei Orgânica da Assistência Social (Loas). 
O quarto momento inicia-se em 2001, penúltimo ano do governo do presidente Fernando Henrique Cardoso, já em seu segundo mandato. Esse é o momento da expansão dos programas de iniciativa do governo federal em desenvolvimento e a criação de novos, com destaque ao Bolsa Escola e ao Bolsa Alimentação. Esses programas foram implementados de modo descentralizado e alcançaram a maioria dos 5.561 municípios brasileiros.

O ano de 2003, quando se inicia o primeiro mandato do governo do presidente Luiz Inácio Lula da Silva, é o início de um quinto momento na história do desenvolvimento dos Programas de Transferência de Renda no Brasil. Neste contexto, o Programa Bolsa Família (PBF) foi instituído pela Medida Provisória ํㅜ 132, em outubro de 2003, pelo governo federal, logo transformada em lei — Lei no 10.836, de 9 de janeiro de 2004 (Brasil, 2009), como programa de transferência de renda, que faz parte da estratégia de combate à pobreza do Fome Zero, desenvolvido pelo Ministério do Desenvolvimento Social e Combate à Fome (MDS) (Stein, 2008). Por meio dele o governo buscou integrar os programas existentes até então, como o Bolsa Escola, o Programa Nacional de Acesso a Alimentação, o Bolsa Alimentação e o Programa Auxílio-Gás. Em resumo, o quinto e atual momento na construção histórica dos Programas de Transferência de Renda é marcado por duas mudanças importantes: ampliação do público atendido pelos programas federais, com elevação significativa dos recursos a eles destinados, e proposta de unificação dos programas federais, estaduais e municipais. Nesse sentido, já podemos falar na instituição de uma Política Nacional de Transferência de Renda, constituindo-se no eixo central da proteção social no Brasil.

Este programa busca ainda cumprir com o compromisso assinado pelo Brasil, juntamente com outros países, de atingir as "Metas de Desenvolvimento do Milênio" até o ano de 2015 (Nações Unidas, 2000; Stein, 2008). Essas metas foram criadas para promover "esforços mundiais para reduzir a pobreza, melhorar a saúde e promover a paz, os direitos humanos e a sustentabilidade ambiental" (Stein, 2008:200).

No Brasil, o governo utiliza, como medida de inclusão no Programa Bolsa Família, a renda mensal per capita, com faixas que determinam pobres e extremamente pobres. A inserção das famílias no PBF é feita mediante sua inscrição no Cadastro Único, de gestão municipal, de onde são selecionados de acordo com os critérios do governo federal para o recebimento do benefício. Existem três tipos de benefícios: o básico, o variável e o variável vinculado ao adolescente (Brasil, 2009).

O PBF possui ainda condicionalidades necessárias para a manutenção do benefício, sendo obrigação da família que crianças e adolescentes em idade escolar frequentem as aulas e cumpram com os cuidados básicos de saúde como vacinação e acompanhamento nos postos de saúde. Estas condicionalidades devem ser controladas pelos gestores municipais que coordenam a execução do programa nas diversas localidades em que o mesmo está sendo desenvolvido.

É com esse programa que o governo busca diminuir a desigualdade social de modo que todos sejam reconhecidos como cidadãos, indistintamente. Esse é um caminho que já está sendo trilhado, porém ainda está longe "do estágio sustentável de inclusão social" (Weissheimer, 2006:40). A inclusão no mercado de trabalho formal e/ou informal, de modo a garantir 
a renda, ainda está dando passos muito curtos, o que impede um avanço maior, especialmente considerando-se a existência do desemprego estrutural. Somente com sujeitos emancipados e autônomos é que se poderá almejar um patamar de igualdade de direitos.

A redistribuição da renda por meio de programas de transferência é, sem dúvida, paliativa diante das necessidades existentes, porém pode constituir um recurso importante para possibilitar sua saída do círculo vicioso da pobreza. Entende-se por círculo vicioso da pobreza a falta de investimentos na melhoria e mudanças das condições de vida, mantendo-se assim uma população estagnada na situação de pobreza em que se encontra, ou seja, por não ter condições financeiras de investir em melhores condições de vestuário, de moradia, de alimentação, de educação, entre tantas outras necessidades (Mantega, 1984; Silva, Yazbek e Giovanni, 2006). Ela perpassa gerações, causando assim um ciclo intergeracional de pobreza, quando não se vislumbram mudanças nesse patamar devido às possibilidades que lhes são oferecidas. É preciso romper com esse ciclo dando às famílias que se encontram envolvidas nele condições financeiras e de acesso a meios qualificados que possibilitem que elas avancem e não retornem ao ponto de partida.

\section{Compreendendo a pobreza}

Apesar de estar presente no cotidiano de todas as cidades, a pobreza pode ter diferentes significados e formas de expressão, dependendo do local, do tempo histórico e do entendimento de cada grupo humano sobre o assunto (Chambers, 2008). De forma abrangente, ela pode ser compreendida como a impossibilidade de ter "condições de viver dentro dos padrões socialmente estabelecidos" em um determinado momento histórico (Stotz, 2005:53). Uma situação de condições precárias, que dificulta as mudanças que possibilitariam atingir tais padrões de vida, entendidos como "as condições objetivas de viver com um nível de dignidade ou de acesso a serviços públicos e privados" (Sposati, 1997:22).

Tradicionalmente, as condições precárias que causam uma situação de pobreza são atribuídas à baixa renda. Mas existem diversos conceitos e concepções mais amplos sobre a pobreza, que se refletem, por exemplo, em diferentes tipos de indicadores (Rolin et al., 2006). O quadro 1 apresenta algumas dessas concepções.

O Programa das Nações Unidas para o Desenvolvimento (Pnud, 1997) entende a pobreza como multidimensional, por estar relacionada a múltiplas formas de privações e não apenas à renda (considerada unidimensional). Define pobreza como a falta de acesso e recursos (não apenas financeiros) que possibilitem um padrão de vida em que sejam supridas as necessidades básicas, como alimentação, higiene, vestuário, educação, lazer (Pnud, 2000). São pobres aqueles sujeitos que, além de não possuírem renda suficiente para satisfação de suas necessidades e nem acesso a alternativas para satisfazê-las, não são valorizados e respeitados como cidadãos. 
Quadro 1

\section{Características das concepções de pobreza}

\begin{tabular}{|c|c|c|c|}
\hline $\begin{array}{l}\text { Concepções de } \\
\text { pobreza }\end{array}$ & $\begin{array}{c}\text { Indicador } \\
\text { predominante }\end{array}$ & São pobres & Principais índices \\
\hline Renda (Income) & Meio & $\begin{array}{l}\text { Os que têm uma renda pessoal ou familiar } \\
\text { abaixo de um determinado nível. }\end{array}$ & $\begin{array}{l}\text { Renda per capita; derivados de } \\
\text { uma linha de pobreza: incidência de } \\
\text { pobreza (Headcount index); Poverty } \\
\text { gap; Squared poverty gap. }\end{array}$ \\
\hline $\begin{array}{l}\text { Necessidades } \\
\text { básicas (Basic } \\
\text { needs) }\end{array}$ & Meio & $\begin{array}{l}\text { Os que não têm condições, em especial } \\
\text { materiais, de atingir as necessidades humanas } \\
\text { básicas. }\end{array}$ & $\begin{array}{l}\text { Índice de Desenvolvimento Humano } \\
\text { (IDH), Índice de Pobreza Humana } \\
\text { (IPH). }\end{array}$ \\
\hline $\begin{array}{l}\text { Capacitação Hu- } \\
\text { mana (Human } \\
\text { capability) }\end{array}$ & Fim & $\begin{array}{l}\text { Os que não possuem habilidades e } \\
\text { oportunidades mínimas para viver em um } \\
\text { nível aceitável dentro de uma sociedade } \\
\text { (ênfase nas capacidades e oportunidades). }\end{array}$ & Capability poverty measure; IPH. \\
\hline $\begin{array}{l}\text { Acesso ao meio } \\
\text { (ativos, equidade, } \\
\text { governança) } \\
\text { (Empowerment) }\end{array}$ & Meio & $\begin{array}{l}\text { Os sem acesso aos ativos (produtivos, infraes- } \\
\text { trutura física e social etc.) } \\
\text { - Equidade } \\
\text { - Governança }\end{array}$ & $\begin{array}{l}\text { Coeficiente de Gini; circulação de } \\
\text { informações; regulamentações; } \\
\text { descentralização. }\end{array}$ \\
\hline
\end{tabular}

Fonte: Rolin e colaboradores (2006:515).

Portanto, na visão do Pnud (2000), a falta de acesso pela negação da possibilidade de escolhas e oportunidades submete a uma condição de vida subalterna. Esta visão de pobreza das Nações Unidas está alinhada com a concepção de Sen (2000) de pobreza como privação das capacidades básicas do ser humano. Capacidades significam a possibilidade de escolher por uma vida que se tem razão de valorizar, em dar oportunidade real para as pessoas promoverem seus objetivos. É uma visão também multidimensional, que não reduz a pobreza ao baixo nível de renda, porém que reconhece sua importância, "uma vez que a renda é um meio importantíssimo de obter capacidades" (Sen, 2000:112).

Considerar a pobreza como privação de capacidades é particularmente relevante quando se analisam as iniciativas públicas que visam à redução da pobreza, também por auxiliar no entendimento da relação entre baixa capacidade e baixa renda (Sen, 2000). De fato,

a relação entre renda e capacidade seria acentuadamente afetada pela idade da pessoa (por exemplo, pelas necessidades específicas dos idosos e dos mais jovens), pelos papéis sexuais e sociais (por exemplo, as responsabilidades especiais da maternidade e também as obrigações familiares determinadas pelo costume), pela localização (por exemplo, pela propensão a inundações ou secas, ou insegurança e violência em alguns bairros pobres e muito populosos), pelas condições epidemiológicas (por exemplo, doenças endêmicas em uma região) e por outras variações sobre as quais uma pessoa pode não ter controle ou apenas um controle limitado. (Sen, 2000:110)

Sen (2000) argumenta que certas desvantagens (por exemplo, idade avançada, doença, baixa educação) reduzem o potencial de o indivíduo auferir renda, mas também tornam mais 
difícil converter renda em capacidade. Esta seria uma situação de "pobreza real" de privação de capacidade, mais intensa do que o simples problema da renda. De fato, uma pessoa desempregada pode receber auxílio-desemprego e dessa forma ter renda suficiente para sua subsistência. Mesmo assim, poderia ser privada de suas capacidades por outras consequências negativas geradas pela situação de desemprego, como "dano psicológico, perda de motivação para o trabalho, perda de habilidade e autoconfiança, aumento de doenças e morbidez (...), perturbação das relações familiares e da vida social, intensificação e acentuação de tensões raciais e de assimetrias entre os sexos" (Sen, 2000:117). Dessa forma, programas de transferência de renda (como o Bolsa Família) não garantem, por si só, o desenvolvimento de capacidades por atenuar o problema da renda, mas precisam ser conduzidos em conjunto com outras ações para promover esse objetivo.

Por isso, Sen (2000) destaca a importância de que a redução de renda não pode ser vista como a principal motivação das políticas públicas de combate à pobreza. Investir em educação, saúde etc. para reduzir a pobreza de renda seria confundir os fins com os meios. "O que a perspectiva da capacidade faz na análise da pobreza é melhorar o entendimento da natureza e das causas da pobreza e privação desviando a atenção dos meios (...) para os fins que as pessoas têm razão para buscar e, correspondentemente, para as liberdades de poder alcançar estes fins" (Sen, 2000:112). E essa liberdade passa pela autonomia necessária para exercer tal liberdade.

\section{Autonomia e liberdade}

A preocupação com a liberdade tem sido objeto de estudos e controvérsias através dos séculos entre pensadores e não é o objetivo aqui entrar no âmbito desse debate. Como propõe Sen (2002), seria um erro olhar para uma "autêntica" caracterização da ideia básica de liberdade, pois o conceito de liberdade inclui uma diversidade de preocupações dentro de um corpo amplo. Porém, o autor afirma que é difícil pensar nas excelências ou nas limitações de uma sociedade, ou ainda no que está certo ou errado em arranjos sociais, sem entrar, de uma maneira ou de outra, na discussão sobre a liberdade. Nesta pesquisa, aborda-se brevemente a liberdade na visão de Sen $(2000,2002)$ para estruturar o conceito de autonomia que foi utilizado.

A liberdade pode ser estimada pela oportunidade gerada na busca das metas e objetivos das pessoas. Analisando as oportunidades, deve-se prestar atenção na real habilidade da pessoa em adquirir aquilo que ela tem motivos em valorizar. Neste contexto específico, o foco não está diretamente no processo envolvido que gera a liberdade, mas em quais são as oportunidades reais de realização das pessoas envolvidas (Sen, 2002).

Assim, de acordo com o exposto na seção anterior sobre pobreza, um dos tipos de liberdade é aquela de poder alcançar os fins, a partir do desenvolvimento de capacidades que os permitam um indivíduo viver de acordo com o que valoriza (Sen, 2000). Para o autor,

a "capacidade" [capability] de uma pessoa consiste nas combinações alternativas de funcionamentos cuja realização é factível para ela. Portanto, a capacidade é um tipo de liberdade: a 
liberdade substantiva de realizar combinações alternativas de funcionamento (ou, menos formalmente expresso, a liberdade para ter estilos de vida diversos). (Sen, 2000:95)

A abordagem de Sen (2000) foca uma liberdade positiva, relacionada com a real habilidade da pessoa de ser ou realizar algo. O autor relaciona essa liberdade com o conceito de desenvolvimento, destacando que o crescimento econômico não pode ser um fim em si mesmo, devendo estar relacionado "com a qualidade de vida que levamos e com a liberdade que desfrutamos" (Sen, 2000:29). Também aborda as formas de privação da liberdade, derivada de problemas relacionados com a fome, serviços de saúde, acesso a água, desemprego, educação, segurança etc., que afetam um número significativo de seres humanos (Sen, 2000).

Conceitos diferentes sobre autonomia têm sido utilizados em variados campos do conhecimento. Estudos podem ser encontrados principalmente na psicologia (teoria da autodeterminação), na educação e na área da saúde. Em pesquisas sociais sobre pobreza, o uso do termo é mais restrito. Nesta linha, para Ribeiro (2006:180), autonomia pode ser entendida como a "capacidade do indivíduo de se autossuprir, desde o mínimo de sobrevivência até as necessidades mais específicas". Pereira (2002:71) complementa esse conceito acrescentando que "autonomia não é só ser livre para agir como bem se entender, mas, acima de tudo, é ser capaz de eleger objetivos e crenças, valorá-los e sentir-se responsável por suas decisões e por seus atos". Percebe-se que ambos os autores veem a autonomia como um tipo de capacidade.

Na teoria da autodeterminação (Self-Determination Theory - SDT) da psicologia é onde autonomia constitui um conceito mais pesquisado. A SDT surgiu visando "estabelecer uma psicologia com responsabilidade social e política, de maneira a delinear variáveis que pudessem ser operacionalizadas, inclusive em nível de políticas públicas, com foco em saúde e bem-estar psicológicos" (Appel-Silva, Wendt e Arigimon, 2010:351). Para a SDT, a autonomia é vista como uma necessidade psicológica básica que representa a propensão individual em direção à autogovernança e a um comportamento coerente com o que deseja. A experiência da autonomia estaria associada com o sentimento positivo de ser autor e agente do próprio comportamento, resultando em uma sensação de liberdade. Muitos estudos demonstraram, por sua vez, que a satisfação da necessidade de autonomia tem impacto crucial no bem-estar dos indivíduos. Assim, muitos estudos investigaram a natureza dos eventos sociais que influenciam a sensação individual de autonomia. Exposição a eventos controladores leva os indivíduos a perder seu sentido relativo de autonomia (Chirkov, 2003; Radel et al., 2011).

De acordo com o SDT, a pessoa é autônoma quando seu comportamento é percebido como uma experiência derivada de sua vontade e quando ela endossa totalmente as ações em que está engajada e/ou os valores expressados pelas ações. Assim, pessoas são mais autônomas quando agem de acordo com seus interesses autênticos ou integram seus valores e desejos (Chirkov, 2003; Radel et al., 2011).

Ainda que sejam evidentes as diferenças entre a concepção de liberdade de Sen (2002) e os conceitos de autonomia destacados, afinal, surgem de diferentes campos de conhecimentos com objetivos bem distintos, eles possuem similaridades interessantes para definir o conceito de autonomia utilizado neste artigo. Evidencia-se, contudo, que a base do conceito 
é a visão de pobreza e de liberdade de Sen $(2000,2002)$, sendo os conceitos adicionais do SDT, de Ribeiro (2006) e Pereira (2002) utilizados de forma complementar. Desse modo, autonomia nesta pesquisa é compreendida como a capacidade de o indivíduo superar formas de privação da liberdade que o impedem de viver de acordo com seus desejos e valores.

Em relação a este conceito, destaca-se: (1) que se trata de uma capacidade, seguindo a visão de Sen (2000) e os conceitos de autonomia descritos por Ribeiro (2006) e Pereira (2002); (2) que a finalidade de viver de acordo com seus desejos e valores vai ao encontro tanto da visão de autonomia do SDT (Chirkov, 2003; Radel et al., 2011), quanto da visão de liberdade de Sen (2002), como já abordado neste referencial teórico, e (3) que sua ausência pode ser considerada uma "forma de privação da liberdade", conceito utilizado por Sen (2000), o qual se refere a situações de dificuldades relacionadas com a saúde, educação, alimentação, violência (risco), relações familiares, gênero, convívio social, moradia e trabalho, entre outros.

\section{Método de pesquisa}

A pesquisa tem natureza exploratória e se baseia tanto em dados quantitativos como qualitativos. A coleta de dados qualitativos ocorreu por meio de (1) entrevistas com três profissionais de dois Centros de Referência da Assistência Social (Cras) e (2) entrevistas com quatro famílias beneficiadas. Os dados quantitativos foram coletados a partir da aplicação de questionário em 103 famílias atendidas pelo PBF.

Alinhados com o objetivo do estudo, os roteiros das entrevistas e o questionário foram desenvolvidos com base no referencial teórico visando identificar a contribuição do PBF no enfrentamento da pobreza e na autonomia dos sujeitos beneficiários. Considerando autonomia como a capacidade de o indivíduo superar formas de privação da liberdade que o impede de viver de acordo com seus desejos e valores, os instrumentos procuraram identificar se e como os beneficiários do PBF têm conseguido superar essas formas de privação da liberdade. Nesse sentido, nove aspectos principais foram analisados: alimentação, educação, saúde, relações familiares, risco (incluindo violência), convívio social, moradia, lazer e trabalho (Sen, 2000).

O roteiro de entrevista e o questionário foram avaliados por três especialistas (professores e doutorandos) como processo inicial de validação de face e conteúdo. Adicionalmente, foi realizado um pré-teste do questionário com oito famílias, para que fossem observadas "a compreensão das questões, a verificação de dúvidas e das dificuldades no preenchimento, a necessidade de introdução ou supressão de perguntas" (Barros e Lehfeld, 2000:53).

A pesquisa foi desenvolvida em bairros no município de Porto Alegre. O critério para seleção dos bairros foram os níveis de vulnerabilidade social, indicados pela Fundação de Assistência Social e Cidadania (Fasc) do município. Os dois Centros de Referência da Assistência Social indicados desenvolvem atividades junto às famílias cadastradas no Programa Bolsa Família. 


\subsection{Coleta de dados qualitativos: as entrevistas semiestruturadas}

Os profissionais respondentes da entrevista foram assistentes sociais que realizam acompanhamento às famílias beneficiadas pelo Programa Bolsa Família. Já para a seleção das famílias, foi solicitado àquelas que estavam na sala de espera dos Cras ou de passagem nas instituições e que se dispuseram a responder à pesquisa. $\mathrm{O}$ tempo médio das entrevistas foi 40 minutos com os profissionais e de 15 minutos com as famílias e todas as entrevistas foram gravadas e transcritas. As respondentes das famílias foram mulheres com 31, 34, 37 e 38 anos, sendo elas as pessoas cadastradas e responsáveis pelo recebimento do benefício. Em três delas o número de membros da família soma cinco pessoas e em uma família são nove membros. Duas famílias recebem o benefício desde o seu começo, em 2003, uma começou a receber em 2004 e a outra em 2006.

Conduziu-se a "entrevista não simplesmente como um trabalho de coleta de dados, mas sempre uma situação de interação na qual as informações dadas pelos sujeitos podem ser profundamente afetadas pela natureza de suas relações com o entrevistador" (Minayo, 1999:114).

\subsection{Coleta de dados quantitativos: questionário estruturado}

O questionário fechado foi aplicado em dois fóruns distintos: (1) com famílias beneficiárias do Bolsa Família que participam de grupos de trabalho social, cujo objetivo é orientar e dar suporte às famílias atendidas pelo PBF e (2) com famílias beneficiárias do Bolsa Família que se encontravam na sala de espera para atendimento em CRA dos bairros indicados pela Fasc. O instrumento foi aplicado de forma individual (um membro por família), com uma aproximação dos respondentes através da apresentação de um Termo de Consentimento Informado e o convite para participar da pesquisa. Aqueles que concordaram responderam as questões com o auxílio do pesquisador, no que concerne a esclarecimentos acerca das questões contidas no instrumento. Como nem todos os respondentes eram alfabetizados, a leitura do instrumento foi feita oralmente pelo pesquisador, e as respostas eram facilitadas por serem questões fechadas. O tempo para o preenchimento do questionário foi de, em média, 20 minutos e foram aplicados 103 questionários (99 mulheres e 4 homens) em sete bairros da cidade de Porto Alegre.

A amostra foi definida de forma não probabilística por tipicidade, ou seja, "a hipótese subjacente à escolha de uma comunidade típica é que ela se apresenta típica no que concerne a um conjunto de propriedades" (Marconi e Lakatos, 2002:53); no caso do presente estudo, a inserção no PBF pela situação de vulnerabilidades similares, que são condicionalidades para que estas famílias sejam beneficiárias do mesmo.

A idade dos respondentes variou entre 22 e 64 anos, sendo representantes de famílias numerosas (52,4\% possuem cinco membros ou mais). A maioria era beneficiária do programa 
há mais de quatro anos, período que seria suficiente para que muitas famílias já apresentassem quadros significativos de mudanças se o programa atingisse seus objetivos.

\subsection{Análise dos dados}

Para a realização da análise de conteúdo, as respostas foram interpretadas individualmente, utilizando-se a técnica definida como análise categorial, ou seja, a decodificação em diversos elementos, definidos como "unidades de registro", os quais são classificados formando agrupamentos (Bardin, 1977), no caso específico, a partir do agrupamento em relação às potenciais formas de privação da liberdade (educação, saúde, moradia, trabalho etc.).

Inicialmente, montou-se a grade de análise contendo as respostas dos entrevistados e buscou-se identificar como as categorias teóricas apareciam em cada questão, identificando aproximações e divergências. Posteriormente, verificou-se o surgimento de novas categorias que emanaram da expressão dos sujeitos que, acrescidas às primeiras, permearam os núcleos de significação a partir dos quais se buscou articular inferências e reflexões teóricas. Algumas expressões dos usuários foram explicitadas de modo a dar maior visibilidade a suas opiniões, valorações e sentimentos. Para o tratamento dos dados quantitativos foram utilizadas técnicas usuais de análise estatística, tais como média, distribuição de frequência e análise de variância.

\section{Análise dos resultados}

A análise dos resultados foi estruturada a partir das principais formas de privação analisadas (educação, saúde, trabalho e renda, alimentação, moradia etc.), destacando-se, ainda, a participação dos beneficiários em grupos e atividades de apoio social e a estrutura disponibilizada para execução do PBF nos locais pesquisados. Em cada aspecto, são utilizados tanto os resultados da análise das entrevistas qualitativas com os profissionais e com as famílias, como o resultado do questionário aplicado.

Para se obter uma primeira compreensão da situação geral das famílias, a tabela 1 apresenta as médias das respostas do questionário indicando o grau de melhoria em diversos aspectos da vida familiar que podem constituir formas de privação da liberdade, que impedem o desenvolvimento das capacidades dos indivíduos e, consequentemente, da autonomia. Os dados estão descritos em uma notação de 1 (melhorou muito) a 5 (piorou muito). Pode-se observar que, como todas as médias são inferiores a 3, houve uma percepção geral de melhoria (ainda que isto não se verifique em todas as famílias).

A tabela 1 apresenta ainda a distribuição de frequência das respostas. Para 90,3\% dos respondentes, a situação geral da família melhorou após o recebimento do Bolsa Família. Esse dado é significativo, pois indica que o PBF estaria conseguindo modificar positivamente a vida das famílias beneficiárias, um sinal de efetividade no combate à pobreza. Contudo, quando se 
observam aspectos específicos, nota-se que sua evolução não ocorre na mesma proporção em todas as famílias.

Tabela 1

Percepção de melhoria quanto às situações de vida

\begin{tabular}{|c|c|c|c|c|c|c|}
\hline & Média & $\begin{array}{l}\text { Melhorou } \\
\text { Muito }\end{array}$ & Melhorou & $\begin{array}{c}\text { Nem Melhorou } \\
\text { Nem Piorou }\end{array}$ & Piorou & Piorou Muito \\
\hline Situação geral da família & 1,81 & $30,1 \%(31)$ & $60,2 \%(62)$ & $8,7 \%(9)$ & $1,0 \%(1)$ & $0,0 \%(0)$ \\
\hline Alimentação & 1,95 & $16,5 \%(17)$ & $71,8 \%(74)$ & $11,7 \%(12)$ & $0,0 \%(0)$ & $0,0 \%(0)$ \\
\hline Educação & 2,13 & $9,7 \%(10)$ & $67,0 \%(69)$ & $22,3 \%(23)$ & $0,0 \%(0)$ & $0,0 \%(0)$ \\
\hline Saúde & 2,24 & $8,7 \%(9)$ & $58,3 \%(60)$ & $33,0 \%(34)$ & $0,0 \%(0)$ & $0,0 \%(0)$ \\
\hline Relações familiares & 2,36 & $9,7 \%(10)$ & $50,5 \%(52)$ & $34,0 \%(35)$ & $5,8 \%(6)$ & $0,0 \%(0)$ \\
\hline Risco & 2,38 & $10,7 \%(11)$ & $43,7 \%(45)$ & $42,7 \%(44)$ & $2,9 \%(3)$ & $0,0 \%(0)$ \\
\hline Convívio social & 2,42 & $6,8 \%(7)$ & $42,7 \%(44)$ & $47,6 \%(49)$ & $0,0 \%(0)$ & $0,0 \%(0)$ \\
\hline Moradia & 2,50 & $7,8 \%(8)$ & $40,8 \%(42)$ & $43,7 \%(45)$ & $6,8 \%(7)$ & $0,0 \%(0)$ \\
\hline Lazer & 2,59 & $5,8 \%(6)$ & $32,0 \%(33)$ & $58,3 \%(60)$ & $2,9 \%(3)$ & $0,0 \%(0)$ \\
\hline Trabalho & 2,74 & $2,9 \%(3)$ & $29,1 \%(30)$ & $59,2 \%(61)$ & $6,8 \%(7)$ & $1,0 \%(1)$ \\
\hline Conjunto & & $10,9 \%(112)$ & $49,6 \%(511)$ & $36,1 \%(372)$ & $2,6 \%(27)$ & $0,1 \%(1)$ \\
\hline
\end{tabular}

Fonte: Resultados da pesquisa.

\subsection{Educação}

Na visão das profissionais entrevistadas, a educação é considerada o ponto forte na atenção das famílias, com o cuidado com a presença das crianças e adolescentes na escola. Essa visão é reforçada na pesquisa quantitativa, em que $76,7 \%$ das famílias reconhecem que a situação educacional melhorou depois que começaram a receber o benefício (e nenhuma família indicou uma situação de piora), sendo este um dos aspectos que obteve melhor resultado.

As famílias reconheceram nas entrevistas que estão mais atentas à presença das crianças e adolescentes na escola, com uma expectativa de diminuição da evasão escolar. Por outro lado, apesar de uma família revelar uma mudança nas atitudes dos filhos, que antes eram "mais revoltados" (FAM 01), não se identificaram relatos claros de avanços em relação à aprendizagem. Esta dificuldade de observação pode estar relacionada, entre outros aspectos culturais e de contexto, com a qualidade da educação das escolas nas regiões pesquisadas, criticada pelas profissionais entrevistadas. De qualquer maneira, uma das profissionais afirmou:

AS 01 - (...) elas [as famílias] têm cuidado muito para as crianças ficarem na escola, o que antes não ocorria. Elas comentam isso, que antes não tinham muito acompanhamento na escola e que agora já são um pouco mais exigentes com os filhos para que permaneçam na escola; também porque sabem que é necessário para o BF. Elas sabem que é uma obrigação, mas aos poucos, pelo 
que eu estou percebendo, não fazem só por obrigação, e sim porque criaram essa consciência ao longo do tempo (...).

Na fala da profissional, percebe-se um interessante avanço proporcionado pelo BF que se reflete na forma de pensar das famílias. Como obrigatoriedade, a simples participação dos filhos dos beneficiários na escola não pode ser considerada um avanço na autonomia dos mesmos, pois as famílias não estariam fazendo algo que desejam (com a ressalva de que, num sentido mais amplo, não se está afirmando que as famílias "não valorizavam" a educação das crianças). Entretanto, as entrevistas sugerem que os reflexos positivos da presença das crianças na escola, uma vez percebidos, começaram a ser valorizados pelas famílias. Assim, o que era uma ação obrigatória imposta, passaria a constituir uma opção desejada, aumentando a capacidade da família em propiciar a educação aos filhos e, portanto, aumentando sua autonomia.

\subsection{Saúde}

$\mathrm{Na}$ área da saúde, existe menos consenso em relação aos avanços propiciados pelo PBF nas famílias. Por um lado, as profissionais dos CRAs se posicionaram de forma mais crítica em relação à questão. Destacaram a necessidade de atenção à saúde mental das famílias e minimizaram o resultado apresentado pelo acompanhamento das famílias beneficiadas, que ainda se limita à questão do peso/altura e das vacinas das crianças. Ao citar a saúde mental como um complicador na vida e na organização familiar, visto que muitas se encontram em sofrimento e assim também mais vulneráveis, uma das profissionais salientou a importância de um trabalho voltado especificamente para essa questão para uma melhoria real na qualidade de vida das famílias. O relato da profissional vai ao encontro da visão de Sen (2000), que dá amplo destaque em como complicações de saúde podem comprometer a capacidade das pessoas de se desenvolverem. A visão das profissionais segue uma argumentação de que o PBF é insuficiente para superar um quadro mais complexo dos serviços de saúde oferecidos às comunidades de baixa renda e, portanto, um forte limitador da autonomia dos indivíduos.

Neste contexto, seriam justamente as famílias de maior vulnerabilidade que têm dificuldades para cumprir as condicionalidades e se manter como beneficiárias. Por exemplo, um dos relatos indicou que famílias desestruturadas por problemas de saúde mental teriam dificuldade de garantir a presença das crianças na escola. Saúde e educação, mais do que condicionalidades do PBF, possuem um papel fundamental na autonomia das pessoas em situações de baixa renda. Sen (2000:113) destaca:

Não ocorre apenas que, digamos, melhor educação e serviços de saúde elevem diretamente a qualidade de vida; esses dois fatores também aumentam o potencial de a pessoa auferir renda e assim livrar-se da pobreza medida pela renda. Quanto mais inclusivo for o alcance da educação básica e dos serviços de saúde, maior será a probabilidade de que mesmo os potencialmente pobres tenham uma chance de superar a penúria. 
Por outro lado, as famílias identificaram mais claramente alguns avanços nas questões da saúde a partir do benefício. Isso se refletiu na pesquisa quantitativa, em que $67 \%$ observaram melhorias, enquanto nenhum entrevistado acredita que a situação de saúde tenha piorado (tabela 1). Um exemplo interessante que ilustra essa situação está no relato de uma usuária. Ao ser questionada sobre como o BF melhorou sua vida, ela respondeu que não tem mais dor nas costas, por ter conseguido comprar o encanamento de água e não precisar mais buscar água com balde na cabeça, além de ter comprado um colchão. Esse exemplo ajuda a mostrar que a família, ao administrar o benefício, busca sanar suas dificuldades de acordo com o que é prioritário para ela naquele momento, diferentemente de auxílios que eram direcionados para o leite, o gás ou alimentos, quando na verdade a prioridade poderia ser outra. A administração do dinheiro por parte das famílias permite assim um avanço no desenvolvimento de sua autonomia, pois elas adquirem a capacidade de realizar o que efetivamente desejam e valorizam.

As famílias também revelam que nem todas têm o acompanhamento de saúde como deveriam, como condicionalidade ao benefício. Obviamente, as famílias não deixam de ser atendidas pelo SUS caso precisem, mas não há um acompanhamento direcionado ao BF de modo a registrar as situações familiares com o intuito de promover ações de intervenção, com vistas à superação de tais problemáticas. De forma mais ampla, duas famílias dizem não ter modificado nada em relação às condições de saúde, mas duas dizem ter melhorado, e uma salienta que os filhos estão mais saudáveis e estão seguindo as orientações de higiene dadas pela médica:

FAM $1-(.$.$) a doutora me falou, que eles não podem estar de pé descalço naquele local onde$ eu moro, que eles têm mania de jogar bola e tirar os calçados e jogar sem. Ali eles têm que jogar sempre de calçados de preferência e lavar as mãos sempre antes das refeições que é almoço, janta e os cafés. Isso aí eu tô cuidando muito esse negócio de lavar as mãos.

Se as famílias identificam avanços, a situação está longe de ser ideal. Das 103 famílias respondentes, 34\% apresentavam doentes graves que exigiam cuidados especiais e 26,2\% possuem dependentes químicos (usuários de álcool e/ou drogas). Estes dados revelam ainda a grande vulnerabilidade vivenciada pelas famílias e explicam parte do discurso mais crítico das profissionais em relação à saúde dos beneficiários.

\subsection{Alimentação}

Diversas são as evidências coletadas que mostram que o PBF contribuiu para uma sensível melhoria na alimentação dos beneficiários. Esse foi o aspecto mais bem avaliado na pesquisa quantitativa: $88,3 \%$ dos respondentes indicaram que a alimentação melhorou após o recebimento do benefício. Ao serem questionadas nas entrevistas qualitativas sobre o que o PBF proporcionou ao grupo familiar, duas famílias espontaneamente destacaram a alimentação como aspecto principal. As profissionais dos CRA também foram claras em reconhecer melhorias na alimentação dos beneficiários, que se reflete numa melhor condição de saúde, principalmente das crianças. 
Ao falar sobre as formas de privação da liberdade, Sen (2000:29), que estudou em profundidade as causas da fome no mundo, destaca que "fomes coletivas continuam a ocorrer em determinadas regiões, negando a milhões a liberdade básica de sobreviver. Mesmo nos países em que já não são esporadicamente devastados por fomes coletivas, a subnutrição pode afetar numerosos seres humanos vulneráveis". Ficou evidente que o PBF tem importante contribuição na melhoria da alimentação dos beneficiários e na redução dos casos de desnutrição, e esta é uma contribuição que claramente se reflete na maior autonomia dos sujeitos.

\subsection{Trabalho e renda}

A questão do trabalho e do emprego é oposta àquela relatada sobre a alimentação. Constitui o elemento de privação em que menos as famílias conseguiram avançar, na percepção delas. Quase 60\% dos respondentes indicaram que a situação de trabalho não melhorou nem piorou desde que começaram a receber o benefício, mesmo num contexto favorável da economia (tabela 1). Os resultados são um indício de que o Bolsa Família não tem sido suficiente para muitas famílias conseguirem superar situações de desemprego ou de melhorar suas condições de trabalho, o que seria um aspecto fundamental no enfrentamento à pobreza e no processo de autonomização das famílias, embora para um grupo de $29,1 \%$ a situação tenha melhorado.

Aprofundando a questão relativa ao trabalho, questionou-se sobre a presença ou não de trabalhadores na família e em que situação. Verificou-se um grande número de trabalhadores informais (40,8\%). Muitos não faziam contribuição para a previdência, não estando cobertos em casos de infortúnios que os impeçam de realizar seu trabalho. Situação semelhante deve ocorrer com os trabalhadores autônomos (22,3\%). O benefício é a única forma de renda garantida no sustento de 23,3\% das famílias respondentes, que estavam em situação de desemprego. Apenas 22,3\% encontravam-se inseridas no mercado de trabalho formal.

Nas entrevistas, as profissionais também enfatizaram o desemprego ou situações precárias como um problema para o qual poucos avanços são perceptíveis. Enfatizaram o desejo de as famílias trabalharem e de conseguir um emprego para se manterem sem depender do auxílio do governo. Uma entrevistada afirmou (AS 3): "a maioria dos usuários querem é trabalho, querem ter sua carteira assinada, querem ter os seus direitos garantidos (...) eles querem sim é poder trabalhar e não depender".

Fica claro que existe uma perspectiva dos sujeitos de não dependerem desse recurso. Além disso, também se percebe que às vezes não reconhecem o recurso como um direito, pois entendem que precisam pedir "autorização para o governo" para utilizá-lo. O desemprego se mostra um importante desafio para a autonomia dos sujeitos beneficiários, pois, como já citado, não se trata apenas de renda. O desemprego e o trabalho precário têm sido associados a diversas outras formas de privação que comprometem o desenvolvimento das capacidades, como a perda de autoconfiança, aumento de doenças, perturbação das relações familiares e da vida social, intensificação de assimetrias entre os sexos, para citar apenas alguns exemplos (Sen, 2000). 
A precariedade da renda é exemplificada na fala das famílias entrevistadas. Para uma, o benefício do BF constitui praticamente a única forma de sustento para a manutenção de seus cinco membros. A situação é apenas amenizada pela ajuda financeira esporádica da irmã e por serviços de faxinas que seriam pouco frequentes ultimamente. Para outra família, além do benefício, há o auxílio de um dos filhos adolescentes com 16 anos, que entrega panfletos no final de semana, para o sustento de nove pessoas. Nas outras duas famílias entrevistadas as respondentes encontravam-se trabalhando com carteira assinada, sendo o BF um complemento para a melhoria das condições de vida das mesmas.

\subsection{Moradia}

Buscou-se verificar a situação de moradia das famílias, sendo questionado o número de peças da casa. Identificou-se que $29,1 \%$ das famílias residem em casas com até três peças. Em $8,7 \%$ das residências não há banheiros; dentre aqueles que possuem, 88,3\% têm vaso sanitário e $80,6 \%$ possuem chuveiro. Com relação aos quartos, 6,8\% dizem não haver quartos e para $34 \%$ há apenas um quarto. Quanto ao saneamento ambiental, apenas 3,9\% dizem não possuir água encanada, enquanto que 30,1\% afirmaram não possuir esgoto (e, mesmo para os que possuíam esgoto, este não era tratado), mas todos revelam contar com coleta de lixo. A luz elétrica estava em condição irregular para 65\% dos casos. Estes dados revelam que muitas famílias ainda se encontram em precárias condições de vida. A inexistência de esgoto significa maior vulnerabilidade a contaminações hídricas, especialmente para crianças e idosos, e as ligações elétricas irregulares potenciais riscos de segurança.

Alguns relatos das famílias demonstram, porém, que o PBF tem contribuído para a melhoria da situação de moradia de algumas famílias. Uma das mães entrevistadas disse ter investido na casa comprando material de construção e eletrodomésticos. Relatou que, com a colocação do piso em alguns ambientes, melhorou a saúde do filho que sofre de asma e está tendo menos crises. Observando-se a tabela 1, percebe-se uma divisão na percepção das famílias. Enquanto 48,6\% dos entrevistados afirmaram que a situação da moradia melhorou, para outros $43,7 \%$ a situação não se alterou e houve inclusive 7 casos $(6,8 \%)$ em que ocorreu piora na situação da família.

\subsection{Outras situações (risco, relações familiares, convívio social)}

Embora não destacados pela maioria, mas por concentrações significativas, outros aspectos de igual importância merecem destaque. Dos respondentes, 43,7\% entendem que os riscos a que estão expostos foram reduzidos. Articulando ainda o contingente de 50,5\% que destacou a melhoria nas relações familiares com os $42,7 \%$ que destacaram a melhoria no convívio social, pode-se concluir que houve impacto positivo em sua rede de relações, o que demonstra a relevância das condições materiais de existência para que as famílias possam ressignificar seus modos de vida. 
Alguns relatos no sentido contrário também foram identificados. Vale destacar, por exemplo, a responsabilização da criança pelo benefício (por estar condicionado à presença na escola), gerando situações de pressão e até mesmo de violência:

FAM $03-(\ldots)$ eu não recebi [o auxílio do PBF] no mês de dezembro, mas depois, de lá pra cá eu conversei com eles, dei "uma tunda" em cada um. (...) Eu disse que, se um não recebesse [o auxílio], os outros não iam ganhar [roupa nova], ninguém ganhou. Por culpa dos grandes, os pequenos não ganharam, então, de lá para cá eles estão "tudo direito".

Evidentemente, essa é uma questão que deve ser trabalhada com as famílias de modo a evitar a violência, responsabilizando os pais e não as crianças pela retenção do benefício. Algumas famílias, para não correrem o risco de perderem o benefício, recorrem a estratégias alternativas e muitas vezes acabam se prejudicando:

AS $1-(\ldots)$ eu tenho comentado que está acontecendo, um fenômeno no qual os maridos estão saindo das casas. Todos os maridos estão saindo esse ano, por quê? Porque o marido é o que tem a renda na casa. É uma estratégia delas de sobrevivência, retirar o marido para que a renda continue baixa, porque elas só fazem faxina uma vez por mês, dá $\mathrm{R} \$ 50,00$, então continuam no programa.

Infelizmente, em alguns casos, acaba ocorrendo um retrocesso no processo de emancipação, o que mostra um sinal de dependência, mas também de falta de clareza sobre a proposta do programa. O recebimento de recursos próprios deve servir de base para a melhoria das condições da família, sendo o BF um benefício temporário até que essa família encontre formas de superar as dificuldades. Por outro lado, a fala a seguir ressalta como a autonomia dos sujeitos se desenvolve em outros aspectos a partir do recebimento do benefício:

AS 1 - Com o Bolsa Família elas podem fazer a identidade sem precisar de um atestado de pobreza da assistente social. Elas mesmas já sabem que podem fazer sozinhas as certidões de nascimento de seus filhos. Isso acaba desenvolvendo a autonomia aos pouquinhos. (...) Porque são pessoas, não sei se eu tenho razão, que nunca foram estimuladas a pensar, nunca foram estimuladas a agir por elas mesmas. Sempre recorriam à assistente social para qualquer coisa da vida delas e, por mais que seja meio absurdo dizer: "agora elas conseguem fazer a identidade sozinhas", isso é uma vitória para elas. Assim como ter um cartão do banco, isso emancipa. Elas podem ir lá tirar o dinheiro delas, não precisam da autorização de alguém.

\subsection{Participação em grupos e atividades de apoio social}

Em relação à participação das famílias em grupos e atividades de apoio sociais (tabela 2), mais de 50\% das famílias não responderam à questão, o que leva a inferir que um contingente 
significativo das famílias não se envolve nas atividades e grupos onde deveria ser trabalhada a promoção dos integrantes do grupo familiar. Entre as "outras" atividades que as famílias dizem participar estão: Programa de Erradicação do Trabalho Infantil (Peti); Núcleo de Apoio à Saúde da Família (Nasf); Serviço de Atendimento Socioeducativo (Sase); reuniões do Orçamento Participativo (OP); cursos de artesanato e computação; projeto de reciclagem; Agente Jovem; Cozinha Brasil; Grêmio Show de Bola e consultas no posto de saúde.

Tabela 2

Participação em grupos e atividades

\begin{tabular}{|lcc|}
\hline & Qt. cit. & Freq. \\
\hline Não resposta & 53 & $51,5 \%$ \\
Serviço de Proteção e Atendimento Integral à Família (Paif) & 3 & $2,9 \%$ \\
Grupo de Geração de Renda & 7 & $6,8 \%$ \\
Acompanhamento Mensal & 15 & $14,6 \%$ \\
Reuniões de Grupo & 24 & $23,3 \%$ \\
Cursos Profissionalizantes & 15 & $14,6 \%$ \\
Curso de Alfabetização & 1 & $1,0 \%$ \\
Outro(s) & 19 & $18,4 \%$ \\
TOTAL OBS. & 103 & \\
\hline
\end{tabular}

Fonte: Resultados da pesquisa.

Estas atividades deveriam ser a base para construção da autonomia e do processo de emancipação das famílias, mas elas ainda não atingem a maioria dos beneficiados. Vale relembrar que o PBF prevê não só a transferência de renda, mas sua associação ao trabalho social. O resultado da pesquisa quantitativa mostra que a participação em grupos tem efeito direto na percepção de melhoria da situação da família. As famílias que participam de algum tipo de atividade ou grupo de apoio percebem uma melhoria superior nas condições de vida em comparação com os que não participam (tabela 3). Para confirmar essa afirmação, comparou-se a percepção de melhorias do grupo que participam ou não de grupos e atividades de inclusão (utilizou-se a técnica estatística de Análise da Variância (Anova), que permite examinar as diferenças entre as médias de dois ou mais grupos em estudo, considerando um nível de significância de 95\% — tabela 3). Os dados reforçam a importância da participação em atividades grupais para as famílias na construção de melhores condições de vida.

A partir das entrevistas, percebe-se que a participação em atividades e grupos de apoio é importante para o desenvolvimento de capacidades que possibilitem formas de privação da liberdade. Muitos grupos atuam fortemente em áreas específicas (por exemplo, Peti na erradicação do trabalho infantil, Nasf na saúde etc.). As atividades neles conduzidas - sem entrar no mérito da qualidade - contribuem ao disseminar informações relevantes, ao motivar as famílias para superarem suas dificuldades e, inclusive, ao ampliar a consciência das famílias 
em relação à sua própria condição. Quando somada ao benefício do PBF, a participação nestas atividades e grupos de apoio amplia ainda mais a possibilidade de os indivíduos alcançarem sua autonomia.

Tabela 3

Participação em grupos por situação da família

\begin{tabular}{|lc|}
\hline & Melhoria da situação da família* \\
\hline Não participa de grupos ou não respondeu & 1,94 \\
Participa de grupos & 1,68 \\
TOTAL & 1,81 \\
ANOVA & $\mathrm{p}<.05$ \\
\hline
\end{tabular}

Fonte: Resultados da pesquisa.

* Os parâmetros são estabelecidos sob uma notação de 1 (Melhorou Muito) a 5 (Piorou Muito).

\subsection{Estrutura para execução do Programa Bolsa Família}

Quanto à estrutura disponibilizada pelo poder público para a execução do programa, é possível identificar limitações, iniciando-se pela falta de adequação dos Centros Regionais de Assistência Social em relação ao local de atendimento aos usuários. Foi também citada a falta dos recursos materiais como computadores, acesso a rede de internet e de telefone em alguns locais de atendimento, o que impede o cadastramento das famílias e prejudica o acompanhamento daquelas já cadastradas, além de dificultar os encaminhamentos e articulações com outras políticas e com a rede socioassistencial. O acompanhamento às famílias do BF é feito por estagiários que não são os mesmos que atendem e acompanham as famílias, ocorrendo uma troca de informações de acordo com o interesse do cadastrador e do profissional da ponta, sem nenhum controle ou regularidade para que isso ocorra. Não é feita nenhuma avaliação da situação qualitativa da família onde se identifiquem avanços ou retrocessos que venham a contribuir para a verificação da efetividade do benefício.

A falta desse olhar prejudica as famílias no momento do recadastramento e na manutenção ou cancelamento do BF, pois não reflete os processos pelos quais as famílias estão passando, suas forças e fraquezas, o que precisa ou não ser potencializado para chegarem ao patamar de autonomia e poderem ser desligadas com resultados mais efetivos.

Para a melhoria do PBF as profissionais sugerem: cursos de geração de renda; a participação dos usuários para pensar o programa e suas melhorias, com um valor regionalizado de acordo com o custo de vida de cada local; maior clareza e um trabalho efetivo e de qualidade para a autonomia dos usuários; gestão clara do programa; avaliação e monitoramento permanentes; qualificação do serviço público; garantia do programa como direito e implantação dos CRAs. 
Por sua vez, como sugestão de melhora para o PBF, as famílias apontam a necessidade da continuidade do programa, o aumento do valor recebido, o desenvolvimento de cursos que auxiliem para o emprego e a existência de um local em que as mães possam opinar e serem ouvidas. Para o seu desligamento dizem ser necessário estar bem empregadas, recebendo um salário ou renda fixa suficiente para seu sustento e melhorar as condições da casa. O desligamento aparece como uma perda significativa na vida das famílias, mas elas, apesar de demonstrarem que passariam por dificuldades, têm presente que este benefício pode se encerrar e que outras pessoas também têm necessidade e precisam do mesmo auxílio.

\section{Considerações finais}

Não se pode negar o impacto de um programa que atinge mais de 13 milhões de famílias (Brasil, 2012) a partir da transferência de renda. E exatamente por sua relevância, muitas são as produções sobre a temática que destacam aspectos positivos e negativos acerca do mesmo. Este estudo busca contribuir trazendo novas reflexões através do aporte de dados que explicitam opiniões de profissionais que atuam nos CRAs e dos sujeitos beneficiários. Os resultados sugerem que o programa tem contribuído para a autonomia dos sujeitos no sentido de que colabora para o desenvolvimento de suas capacidades, permitindo superar importantes formas de privação para construir uma vida mais próxima do que almejam e valorizam.

Por outro lado, também fica claro que o PBF não é suficiente para garantir a autonomia dos indivíduos. Mesmo recebendo o benefício, muitas famílias são incapazes de superar alguns problemas relacionados à saúde, moradia, trabalho, entre outros que afligem a população mais vulnerável. De fato, não se espera que apenas por meio da distribuição de renda todas as capacidades sejam desenvolvidas. A transferência de renda permite a muitas famílias beneficiárias melhorarem suas condições de vida, através de uma alimentação mais adequada, melhorias na moradia, aquisição de bens de consumo, entre outros aspectos. Porém, apenas a transferência de renda não basta para a realização de uma mudança efetiva nas condições e no modo de vida das famílias que dela necessitam.

Nesse sentido, o papel das atividades de promoção e apoio das famílias é fundamental, porque atua em paralelo com o aumento da renda para potencializar seus benefícios no desenvolvimento de capacidades que permitam resolver problemas específicos (relacionados com a saúde, educação, moradia, trabalho etc.). De acordo com os dados levantados, as famílias que relataram participação mais efetiva nas atividades e nos grupos de apoio apresentam uma percepção maior em relação às melhorias em suas condições de vida. Essas atividades, portanto, contribuem para o desenvolvimento da autonomia e podem ser compreendidas como o principal mecanismo do programa para as pessoas encontrarem as "portas de saída".

Entretanto, a participação das famílias nas atividades e grupos de apoio existentes apresentou-se incipiente. Essa fragilidade dificulta a ruptura com o ciclo intergeracional de pobreza tendendo ao seu contrário, ou seja, promoção da dependência dos mesmos a um auxílio financeiro. 
Os programas complementares à transferência de renda se caracterizam pela articulação de ações organizadas e regulares que promovem às famílias beneficiárias oportunidades e condições para superar a pobreza de forma sustentável. Abrange diferentes áreas como educação, trabalho, cultura, microcrédito, capacitação e melhoria das condições habitacionais. São exemplos dessas ações os programas para alfabetização e aumento de escolaridade, qualificação e inserção profissional, formação de microempreendimentos, concessão de microcrédito, estratégias de apoio à aquisição, construção ou reforma de unidade habitacional, produção e acesso à cultura e emissão de documentos de identificação civil. Entretanto, tais programas complementares, apesar de diretamente ligados ao PBF, estão fora da alçada direta do programa e dependem da ação de outros ministérios, além do Ministério de Desenvolvimento Social.

Os resultados apresentados devem ser observados dentro dos limites da pesquisa. Destaca-se, sobretudo, que refletem a realidade local de alguns bairros de Porto Alegre. Considerando que a pobreza possui particularidades regionais importantes, é possível (e mesmo provável) que a contribuição do PBF no combate à pobreza e para a autonomia dos sujeitos beneficiários apresente diferenças significativas em outros locais. Neste sentido, estudos futuros que procurem identificar estas diferenças são encorajados. Compreender melhor o papel das atividades e das ações desenvolvidas pelos grupos de apoio na autonomia dos sujeitos, incluindo aquelas que poderiam ser executadas pelos CRAs, também constitui importante possibilidade de pesquisa.

\section{Referências}

APPEL-SILVA, Marli; WENDT, Guilherme; ARIGIMON, Irani I. L. A teoria da autodeterminação e as influências socioculturais sobre a identidade. Psicologia em Revista, v. 16, n. 2, p. 351-369, ago. 2010.

BARDIN, L. Análise de conteúdo. Lisboa: Edições 70, 1977.

BARROS, Aidil J. P.; LEHFELD, Neide A. S. Projeto de pesquisa: propostas metodológicas. São Paulo: Vozes, 2000.

BRASIL. Lei $n^{\circ}$ 10.836, de 9 de janeiro de 2004. Cria o Programa Bolsa Família e dá outras providências. Disponível em: <www.planalto.gov.br/ccivil_03/_Ato2004-2006/2004/Lei/L10.836.htm>. Acesso em: 3 set. 2009.

BRASIL. Ministério do Desenvolvimento Social e Combate a Fome (MDS). O Programa Bolsa Família — PBF. Disponível em: <www.mds.gov.br/bolsafamilia/> . Acesso em: 16 ago. 2012.

CHAMBERS, Robert. What is poverty? Who ask? Who answers? In: Internatinal Poverty Centre poverty in focus. UK. Dez. 2006. Disponível em: <www.undp-povertycentre.org/pub/IPCPovertyInFocus9.pdf>. Acesso em: 14 abr. 2008.

CHIRKOV, Valery et al. Differentiating autonomy from individualism and independence: a self-determination theory perspective on internalization of cultural orientation and well-being. Journal of Personality and Social Psycology, v. 84, n.1, p. 97-110, 2003. 
FGV. Fundação Getulio Vargas. Indicadores de pobreza. In: Indicadores sociais. Disponível em: <http://fgvdados.fgv.br/>. Acesso em: 23 ago. 2012.

MANTEGA, Guido. A economia política brasileira. São Paulo: Vozes, 1984.

MARCONI, Maria A.; LAKATOS, Eva M. Técnicas de pesquisa. São Paulo: Atlas, 2002.

MINAYO, Maria C. de S. O desafio do conhecimento: pesquisa qualitativa em saúde. 6. ed. São Paulo: Hucitec; Abrasco, 1999.

NAÇÕES UNIDAS. Declaração do milênio. Lisboa: United Nations Information Centre, 2000.

PEREIRA, Potyara A. P. Necessidades humanas: subsídios à crítica dos mínimos sociais. São Paulo: Cortez, 2002.

PNUD. Glossário de direitos humanos e desenvolvimento humano. In: PNUD. Relatório do desenvolvimento humano 2000. Brasília: 2000. Disponível em: <www.pnud.org.br/HDR/RelatoriosDesenvolvimento-Humano-Globais.aspx >. Acesso em: 14 jun. 2008.

PNUD. Programa das Nações Unidas para o Desenvolvimento. Glossário da pobreza e desenvolvimento humano. In: PNUD. Relatório do desenvolvimento humano 1997. Brasília: 1997. Disponível em: <www.pnud.org.br/hdr/hdr97/rdh7-1.htm>. Acesso em: 23 maio 2008.

RADEL, Rémi et al. Restoration process of the need for autonomy: the early alarm stage. Journal of Personalisty and Social Psychology, v. 101, n. 5, p. 919-934, 2011.

RIBEIRO, Eveline Alves. Análise das categorias cidadania/direitos, pobreza e assistência social no discurso oficial do Programa Fome Zero. Emancipação, v. 6, n. 1, p. 163-188, 2006.

ROLIN, Cássio et al. Construção de indicadores de pobreza: aplicação do índice de pobreza humana municipal no estado de Sergipe. Revista Econômica do Nordeste, v. 37, n. 4, p. 512-529, out./dez. 2006.

SEN, Amartya. Desenvolvimento como liberdade. São Paulo: Companhia das Letras, 2000.

SEN, Amartya. Rationality and freedom. Cambridge, Massachusetts: The Belknap Press of Harvard University Press, 2002.

SILVA, Maria O. S. O Bolsa Família: problematizando questões centrais na política de transferência de renda no Brasil. Ciência \& Saúde Coletiva, v. 12, n. 6, p. 1429-1439, dez. 2007.

SILVA, Maria O. S.; YAZBEK, Maria C.; GIOVANNI, Geraldo. A política social brasileira no século XXI: a prevalência dos programas de transferência de renda. São Paulo: Cortez, 2006.

SPOSATI, Aldaíza. Mínimos sociais e seguridade social: uma revolução da consciência da cidadania. Revista Serviço Social \& Sociedade, São Paulo, n. 55, p. 9-38, nov. 1997.

STEIN, Rosa Helena. Configuração recente dos programas de transferência de renda na América Latina: focalização e condicionalidade. In: BOSCHETTI, Ivanete et al. (Org.). Política social no capitalismo: tendências contemporâneas. São Paulo: Cortez, 2008. p. 196-219. 
STOTZ, Eduardo N. Pobreza e capitalismo. In: VALLA, Victor V.; STOTZ, Eduardo N.; ALGEBAILE, Eveline B. Para compreender a pobreza no Brasil. Rio de Janeiro: Contraponto: Escola Nacional de Saúde Pública, 2005. p. 52-72.

WEISSHEIMER, Marco A. Bolsa Família: avanços, limites e possibilidades do programa que está transformando a vida de milhões de famílias no Brasil. São Paulo: Fundação Perceu Abramo, 2006.

Maurício Gregianin Testa é doutor em administração e professor da Faculdade de Administração, Contabilidade e Economia da Pontifícia Universidade Católica do Rio Grande do Sul (PUC-RS). E-mail: mauricio.testa@pucrs.br.

Paula Fronza é mestre em serviço social e assistente social do Instituto Nacional do Seguro Social (INSS). E-mail: pfronza@gmail.com.

Maira Petrini é doutora em administração e professora da Faculdade de Administração, Contabilidade e Economia da Pontifícia Universidade Católica do Rio Grande do Sul (PUC-RS). E-mail: maira.petrini@ pucrs.br.

Jane Cruz Prates é doutora em serviço social e professora da Faculdade de Serviço Social da Pontifícia Universidade Católica do Rio Grande do Sul (PUC-RS). E-mail: jprates@pucrs.br. 
